\title{
Producing Diversity: Agroforests Sustain Avian Richness and Abundance in India's Western Ghats
}

\section{OPEN ACCESS}

Edited by:

Enrico Di Minin,

University of Helsinki, Finland

Reviewed by:

Felix Herzog,

Agroscope, Switzerland

Ainhoa Magrach,

ETH Zurich, Switzerland

*Correspondence:

Krithi K. Karanth

krithi.karanth@gmail.com

Specialty section:

This article was submitted to

Conservation,

a section of the journal

Frontiers in Ecology and Evolution

Received: 06 June 2016 Accepted: 08 September 2016 Published: 23 September 2016

Citation: Karanth KK, Sankararaman V, Dalvi S,

Srivathsa A, Parameshwaran $R$, Sharma S, Robbins $P$ and Chhatre $A$

(2016) Producing Diversity:

Agroforests Sustain Avian Richness

and Abundance in India's Western

Ghats. Front. Ecol. Evol. 4:111.

doi: 10.3389/fevo.2016.00111

\begin{abstract}
Krithi K. Karanth 1,2,3*, Vishnupriya Sankararaman ${ }^{2,4}$, Shashank Dalvi ${ }^{2,4}$, Arjun Srivathsa ${ }^{2,4,5}$, Ravishankar Parameshwaran ${ }^{2,4}$, Sushma Sharma ${ }^{2,4}$, Paul Robbins ${ }^{6}$ and Ashwini Chhatre ${ }^{7,8}$

${ }^{1}$ Wildlife Conservation Society, New York, NY, USA, ${ }^{2}$ Centre for Wildlife Studies, Bangalore, India, ${ }^{3}$ Environmental Science and Policy, Nicholas School of the Environment, Duke University, Durham, NC, USA, ${ }^{4}$ India Program, Wildlife Conservation Society, Bangalore, India, ${ }^{5}$ Department of Wildlife Ecology and Conservation, School of Natural Resources and Environment, University of Florida, Gainesville, FL, USA, ${ }^{6}$ Nelson Institute for Environmental Studies, University of Wisconsin-Madison, Madison, WI, USA, ${ }^{7}$ Indian School of Business, Hyderabad, India, ${ }^{8}$ Department of Geography and Geographic Information Science, University of Illinois at Urbana-Champaign, Champaign-Urbana, IL, USA
\end{abstract}

Globally, protected areas have long been the corner stone of biodiversity conservation efforts. In India's Western Ghats, small and isolated protected areas are embedded in a matrix of multiple land-uses, most of which include agroforests. These agroforests are being increasingly recognized for their supplementary role in conserving wildlife. We examined bird species richness and densities in areca (Areca catechu), coffee (Coffea arabica and Coffea canephora) and rubber (Hevea brasiliensis) agroforests in the Western Ghats. We developed a priori hypotheses, predicting that bird species richness and guild density would be highest in coffee, followed by areca and rubber agroforests. We carried out 551 point-count surveys involving 386 hours of sampling in 187 agroforests across a $29,634 \mathrm{~km}^{2}$ area of the Ghats. We observed 204 bird species, of which 170 were residents. The average estimated richness per agroforest was higher in coffee (60.5) compared to rubber (45.4) and areca (34.1). We modeled species richness as a function of relevant biogeographic and environmental covariates. The most influential factors were tree cover, tree density and rainfall in all agroforests, but the strength of these effects varied. Coffee supported higher densities in all four habitat and three feeding guilds compared to areca and rubber. We integrated extensive field sampling with modeling that accounted for imperfect detection, while assessing bird richness and densities across multiple agroforest types. We establish that coffee agroforests are substantially richer in birds than rubber and areca, but all three agroforests play an important role in providing subsidiary habitats for birds in the Ghats. Policy decisions and markets must incorporate such biodiversity values and services provided by these agroforests to sustain and facilitate long-term biodiversity conservation.

Keywords: agroforest, biodiversity, birds, Ghats, India, richness 


\section{INTRODUCTION}

Agroforests and cultivated areas are now globally recognized as important habitats for biodiversity (Balmford et al., 2005; Fischer et al., 2008; Beaudrot et al., 2016). Covering 38\% of the planet's landmass, production landscapes such as tea, coffee, rubber, cacao, arecanut, and rice are known to support a diversity of birds, mammals, amphibians and other ecologically sensitive species in the tropics (Bhagwat et al., 2005; Faria et al., 2006; Perfecto and Vandermeer, 2008; Gardner et al., 2009; Anand et al., 2010; Foley et al., 2011; Robbins et al., 2015; Warren-Thomas et al., 2015). These human-cultivated landscapes support particular species or taxonomic groups, making it essential to understand which species persist and why they persist in such habitats (Daily et al., 2001; Bhagwat et al., 2008; de Lima et al., 2013; Maas et al., 2013; Mendenhall et al., 2014; Pryde et al., 2016). Incorporating such agroforests, which provide secondary habitats could be an important strategy for biodiversity conservation, particularly in Asia where protected areas are small, isolated and fragmented.

In India, small protected areas that house viable source populations of many wildlife species (including endangered tigers and elephants) are embedded in matrices of cultivated agroforestry landscapes (Bhagwat et al., 2005; Robbins et al., 2015). While these protected areas typify a land-sparing approach, the adjacent agroforests support wildlife occurrence and movement. They may help maintain ecosystem processes and biological diversity without necessarily minimizing optimum production from these agroforests (Tscharntke et al., 2012). Intensification of management practices in agroforests may cause cascading effects on surrounding biodiversity.

Several studies have demonstrated that agroforest landscapes could help "produce" wildlife and provide conservation opportunities (Bali et al., 2007; Anand et al., 2010; Garcia et al., 2010; Ranganathan et al., 2010; Robbins et al., 2015). However, most studies have typically focused on a single taxon and/ a single land use type (Bali et al., 2007; Anand et al., 2008; Ranganathan et al., 2008). For facilitating development of realistic conservation policy and management decisions governing these landscapes, it is essential to examine how taxon and guild-specific sensitivities in multiple land uses at large spatial scales. In this context, questions that remain poorly understood with regard to the role of agroforests in biodiversity conservation include: (1) What species do these landscapes support? (2) How does biodiversity vary across different agroforests? (3) How do densities of functional guilds vary across different agroforest types? and (4) What biogeographic and ecological factors influence patterns of diversity?

We surveyed areca, coffee and rubber agroforests in the Western Ghats to assess richness and densities of non-migrant bird species, and examined the influence of environmental drivers on these patterns. We focused on birds, as they are a wellestablished biodiversity indicator group (Gardner et al., 2009; Larsen et al., 2012). The various components of bird communities play different functional ecological roles including seed dispersal and pest control (Karp et al., 2012; Mulwa et al., 2012). The altered environment in human-modified landscapes influences bird communities in positive or negative ways depending on the biology of each functional group (Thiollay, 1995; Clough et al., 2009). Therefore, a common practice used to examine bird community structure is to classify them into feeding guilds and habitat guilds (Thiollay, 1995; Clough et al., 2009). We examined bird assemblages first at the community-level by estimating species richness, then at the level of ecological guilds (by estimating densities at the level of feeding and microhabitat guilds). In doing so, we evaluated the relative potential of coffee, areca and rubber agroforests in sustaining bird diversity. We first made predictions about species richness and guild density in bird communities, and tested them with field data from 187 agroforests.

Some avian studies have examined endemic, rare or range-restricted bird species (Anand et al., 2008; Maas et al., 2009), many others have classified species broadly into forest vs. non-forest dependent species, or habitat specialists vs. generalists, while making such assessments, often without accounting for detectability (Petit and Petit, 2003; Ranganathan et al., 2008). These approaches are criticized, since such broad ecological classifications provide poor predictive power with regard to how individual species or species assemblages respond to habitat loss or land-use change (Ruiz-Gutierrez et al., 2010; de Lima et al., 2013). We have therefore tested our hypothesis on functional guilds of birds rather than on individual species. Due to greater habitat structural complexity and larger variety of shade trees grown, we expected species richness and guild diversity to be higher in coffee compared to areca and rubber agroforests (Anand et al., 2010; Garcia et al., 2010; Ranganathan et al., 2010). We predicted that tree species richness, tree density and percentage tree cover would positively influence bird species richness. We also expected rainfall to be associated with higher species richness. Elevation is known to have a mid-domain effect on diversity, with medium elevation areas supporting higher species richness compared to higher and lower elevations (Wu et al., 2013). In our landscape, we expected elevation to have a positive influence on richness in areca, negative influence in coffee, and no influence in rubber agroforests, based on the different altitudes at which these crops are typically grown. Distance to forest patches or protected areas was expected to influence bird species richness negatively (Anand et al., 2010).

\section{METHODS}

\section{Study Area}

Areca, coffee and rubber agroforests comprise three of the largest commodity agroforest systems in the Western Ghats of Karnataka, a biodiversity hotspot in India that is also densely populated (Das et al., 2006; Robbins et al., 2015). Together, these three agroforest types cover almost $10,000 \mathrm{~km}^{2}$ and produce 258,000 metric tons of areca, 211,100 metric tons of coffee and 700,000 metric tons of rubber every year (Coffee Board of India, 2013; Ministry of Agriculture, 2013; Rubber Board of India, 2013). Karnataka state contributes to $69 \%$ of coffee production, $53 \%$ of areca production and 3\% rubber production in India (Robbins et al., 2015). 
Protected areas cover $<9 \%$ of the $160,000 \mathrm{~km}^{2}$ of the Western Ghats area, making it critical to assess the role of agroforests in biodiversity conservation. This is compounded by various extractive and non-extractive uses by people (Das et al., 2006; DeFries et al., 2010). With a documented $40 \%$ decrease in forest cover, and four-fold increase in number of forest patches over the last 70 years, the Ghats are one of the oldest global humanmodified landscapes and key repositories of biodiversity (Menon and Bawa, 1997). The region is still characterized by high habitat structural complexity and heterogeneity with considerable native forest cover (Das et al., 2006; Anand et al., 2010). The diversity of agroforests in the Ghats embedded in several native forest patches allows us to examine bird richness and abundance as a function of local and landscape factors in the region.

We sampled 187 areca, coffee and rubber agroforests located in seven districts of Karnataka's Western Ghats (Figure 1). The coffee agroforests are usually found in mid to high elevations, and are shade grown under a mixture of native and exotic tree canopy (Anand et al., 2010). Areca is grown at low to mid elevations and is inter-cropped with other commercial species such as coconut, banana and cocoa (Ranganathan et al., 2010). Rubber agroforests however are primarily found in low elevations and are mono-cropped, having no native or introduced species within the cultivated areas (Robbins et al., 2015). The agroforests were selected based on land area and locations in the highest growing administrative units (districts and taluks) in Karnataka and access granted by private landowners. The sampled agroforests ranged in size from 7 to 800 acres across all three agroforests.

\section{Study Design and Field Surveys}

We sampled 65 areca, 61 coffee, and 61 rubber agroforests. We maintained a minimum distance of $1 \mathrm{~km}$ between each sampled agroforest. Sampling was carried out from January to May 2013 in coffee, and November 2013 to March 2014 in areca and rubber. We restricted sampling to the dry season to maximize visibility and improve encounter rates. Since our sampling seasons varied slightly across the 2 years, we excluded migrant species from our analysis as this might influence species composition, inflate densities of some species, and bias overall richness and density estimates.

We used point counts to determine bird species occurrence in each agroforest. The number of points ranged from 2 to 9 in each agroforest, and was proportional to the size of the agroforest. Points were spaced $200 \mathrm{~m}$ apart, to ensure independence between points. At each point, two trained observers recorded all birds that were heard or sighted for $7 \mathrm{~min}$ (following an initial wait period of $2 \mathrm{~min}$ to minimize the effect of disturbance from arrival at the point), and the sighting distance to each bird or clusters of birds was noted. The surveys were conducted between 6:30 a.m. to 9:30 a.m., and 4:00 p.m. to 6:30 p.m., when birds are known to be most active. Each point was revisited six times over 3 days, with this temporal replication helping us achieve adequate numbers of detections (Buckland et al., 2001). We sampled a total of 551 points and the total sampling effort was 386 hours excluding travel time between points and settle-down time at each point.

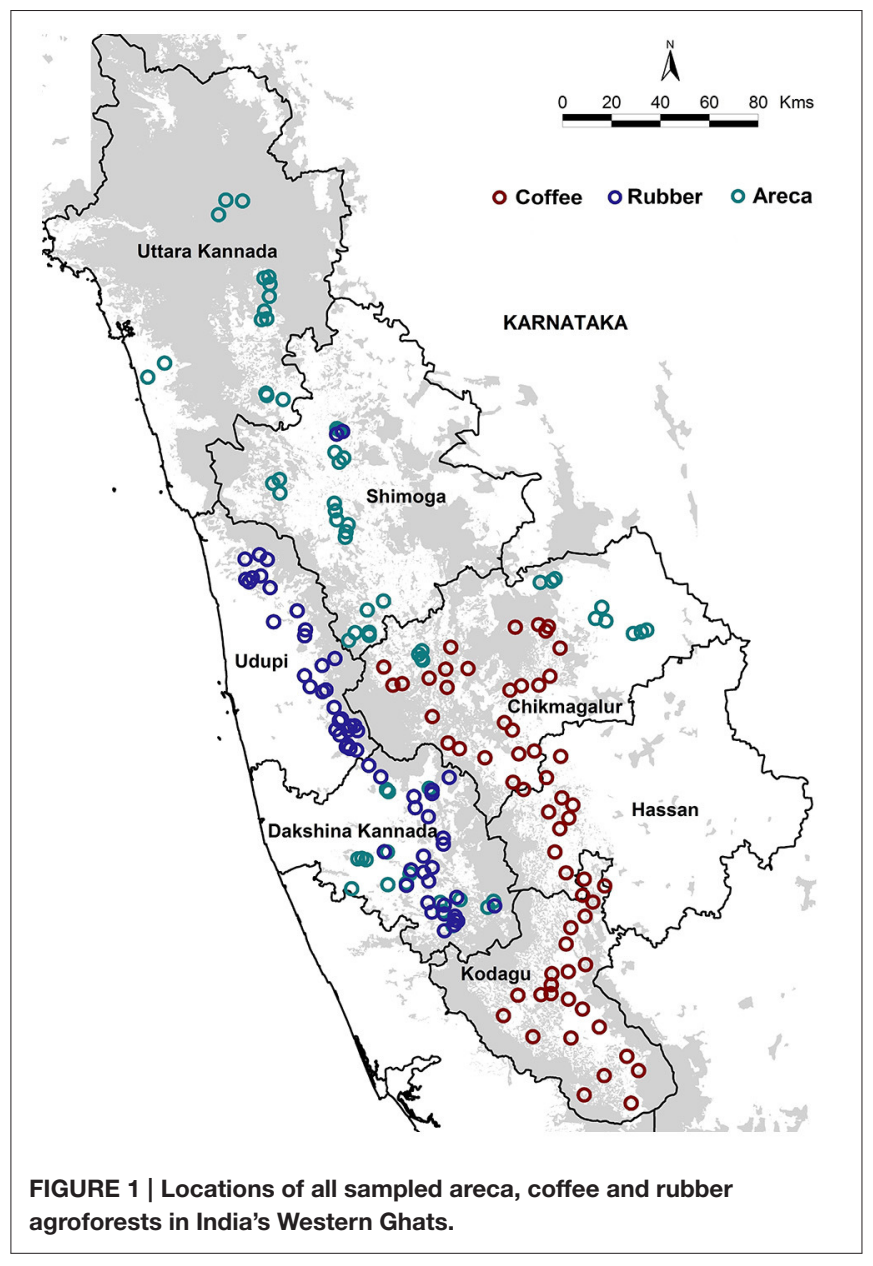

Covariates measured at each point included elevation, slope, weather, canopy structure, canopy density, presence of leaf litter, presence of water bodies and pesticide use. Canopy density was measured in all four cardinal directions at each point using a canopy densitometer. Slope was measured using a compass. Point-centered quarter method was used to estimate tree densities at each point (Runkle, 2000; Mitchell, 2007).

\section{Estimating Bird Species Richness}

Methodological approaches that account for detection probabilities ensure that our parameters of interest such as richness and abundance are not confounded by detectability (Nichols et al., 1998; Cam et al., 2002). When estimating species richness, species-level detectability is a function of the number of individuals present in the sampled area along with their activity patterns, sizes and behavior (Nichols et al., 2008). Therefore, estimates of richness need to incorporate this hetereogeneity in detection probabilities. We first listed all unique species recorded (seen/heard) for each estate. To estimate bird species richness in each agroforest, we used program SPECRICH2. Each species was assigned a " 1 " or " 0 " score each of the six times an agroforest was surveyed (six temporal replicates). SPECRICH2 (Rexstad and Burnham, 1991) uses Burnham's Jackknife estimator to estimate 
richness from 0 to 1 detection histories. Using this information, it estimates the total number of species for each agroforest. Estimates were subsequently averaged across all sites within each agroforest type to enable comparisons between areca, coffee and rubber. We also examined difference in bird species richness between arabica and robusta variants of coffee since they have distinct management practices.

In this study, each agroforest is clustered geographically and their cultivation is constrained by elevation, rainfall, topographic gradients and other characteristics. This may result in spatial autocorrelation of the ecological data. To check for this, we used the Moran's I test on the observed species richness within each agroforest type. The analysis was done in RStudio 3.0.3 (R Development Core Team, 2014), using the package "ape."

\section{Estimating Bird Densities in Feeding and Habitat Guilds}

We assigned each resident bird species observed to a habitat and a feeding guild. We excluded migrant species to avoid inflation in densities of certain guilds and potential biases in overall density estimates. We used seven feeding guilds: bark gleaners, leaf gleaners, salliers, frugivores, granivores, ground feeders, and omnivores, based on food preference in their diet as described in the literature (Ali and Ripley, 1983; Grimmett et al., 1998). Birds were also classified into one of five microhabitat guilds: ground dwelling, low canopy, mid canopy, midhigh canopy and high canopy (Ali and Ripley, 1983; Grimmett et al., 1998).

Bird densities were estimated using point transects (a distance sampling-based approach). This method accounts for partial detectability of target species, by modeling detection probability as a function of distance. The point-transect data were analyzed using program DISTANCE version 6.0 (Buckland et al., 2001; Thomas et al., 2006). Since we were unable to obtain sufficient detections of birds from all guilds from all agroforests, it was not possible to model the detectability separately by speciesagroforest combination. Therefore, we pooled the data for each feeding or habitat guild from all sites of a particular agroforest type, assuming that detectability of birds would be similar within the same agroforest type. We estimated guild-specific densities, treating each agroforest as a separate stratum (Thomas et al., 2006). Subsequently, we used the global detection function (averaging across all sites within an agroforest type, but separate for each guild) to obtain stratumlevel densities (Buckland et al., 2001). We accounted for temporal replication by specifying the number of occasions that each point was surveyed during analyses. Cluster densities and individual bird densities were directly obtained using program DISTANCE for each estate as clusters/hectare and individual birds/hectare.

\section{Modeling Bird Species Richness (SR)}

We modeled sources of variation in species richness based on factors that we expected to influence this parameter of interest using an information theoretic approach. We chose six ecological and biogeographic variables: annual rainfall, distance to nearest protected area, elevation, tree density, tree species richness and percentage tree cover. All variables were normalized (to have mean $=0, \mathrm{sd}=1$ prior to analysis). This allowed us to assess the importance of each covariate by simply comparing the magnitude of the associated beta coefficients. The rainfall data were obtained from Karnataka Directorate of Economics and Statistics. These data were available at the taluk-level (an administrative unit within a district), and an average of 5 sites shared the same rainfall value. Tree density per estate was estimated using point-centered quadrat (PCQ) method (Runkle, 2000). Tree species richness was calculated as a count of unique species within the PCQ plots of each surveyed estate. Percentage tree cover was computed in a $2 \mathrm{~km}$ buffer around each estate using Bhuvan satellite imagery ( $56 \mathrm{~m}$ resolution) obtained from National Remote Sensing Centre, ISRO, India. The land-use classification categories used to calculate percentage tree cover were plantations, evergreen forests, deciduous forests and scrub forests (Melles et al., 2003). Elevation was extracted from ASTER Global Digital Elevation Model with a resolution of $30 \mathrm{~m}$.

We used generalized linear models, treating species richness across estates as the response variable, with Poisson errors. Since our sampling effort was not equal across the study sites (range: 2-9 points), we used $\log$ (effort) as an offset in the regression (Ramsey and Schafer, 2012). We defined a set of 7 candidate models across each agroforest type and developed 3 individual crop-specific models based on our field knowledge. We checked for collinearity among predictor variables prior to analyses and did not use highly cross-correlated variables $(r>0.6)$ within the same model. We assessed and ranked models using Akaike Information Criterion corrected for small sample sizes (AICc; Burnham and Anderson, 2002). The analysis was conducted in RStudio 3.0.3 (R Development Core Team, 2014), using the package "aiccmodavg."

\section{RESULTS}

\section{Species Richness in Agroforests}

From 551 points (each sampled six times) we recorded 204 bird species belonging to 52 families and 18 orders (Supplementary Table 1). We excluded 34 migrant species and we retained 170 resident bird species. Among these 105 were found in areca, 137 in coffee, and 106 in rubber (Table 1). Among 25 reported Western Ghats endemics, we found 11 in rubber and areca, while coffee had12 species (Table 1).

TABLE 1 | Estimated bird species richness across areca, coffee and rubber agroforests.

\begin{tabular}{lccc}
\hline Characteristics & Areca & Coffee & Rubber \\
\hline Sample size (No. of agroforests) & 65 & 61 & 61 \\
Sampling effort (No. of points) & 131 & 274 & 143 \\
Total number of species & 122 & 169 & 127 \\
Total number of resident species & 105 & 137 & 106 \\
Mean estimated species richness (SE) & $34.06(1.76)$ & $58.21(1.85)$ & $45.41(2.1)$
\end{tabular}


Average estimated species richness was highest in coffee $\mathrm{SRc}=58.21(S E=1.85)$ and ranged from 33 to 105 species (Table 1). We compared richness in C. arabica and C. canephora agroforests and found them to be similar $\mathrm{SRca}=58.71$ $(S E=2.55$, range 34-95) in C. arabica and $S R c r=57.67$ in C. canephora ( $S E=2.71$, range 32-91). In Rubber, average estimated bird species richness was $\mathrm{SRr}=45.41$ ( $S E=2.1$, range 11-105). Areca had the lowest richness SRa $=34.06(S E=1.76$, range 8-81).

The results of the Moran's I test found no autocorrelation in either coffee or rubber agroforests. The Moran's I coefficient was very low and $p>0.05$ for both. However, areca agroforests had a negative Moran's I coefficient $(-0.016$; with $p<0.01)$ indicating spatial autocorrelation.

\section{Bird Species Guild Composition and Densities}

We estimated and compared feeding and habitat guild densities in the three agroforests. Across all feeding guilds, detection probabilities varied from 0.12 to 0.39 . Densities of four feeding guilds (bark gleaners, leaf gleaners, salliers, and frugivores) were higher in coffee compared to areca and rubber (Figure 2). Bird densities ranged from 4.32 /ha for frugivores to $0.45 /$ ha for bark gleaners across agroforests. For ground feeders, granivores and omnivores density estimates ranged from 0.11 / ha to 0.23 / ha in coffee. Low encounter rates in areca and rubber prevented us from estimating densities. Among carnivores, encounter rates were too low to estimate densities in all agroforest types.

Among the habitat guilds, encounter rates for ground dwelling birds were too low to estimate densities in all three agroforests; therefore we limited our analysis to the four guilds with adequate data. For habitat guilds, detection probabilities varied from 0.11 to 0.39 . Bird densities were highest in coffee for low canopy, mid canopy and high canopy guilds (Figure 3). Density estimates in coffee ranged from $8.75 /$ ha in high canopy to 0.54 in midlow canopy. However, in mid canopy guilds areca agroforests

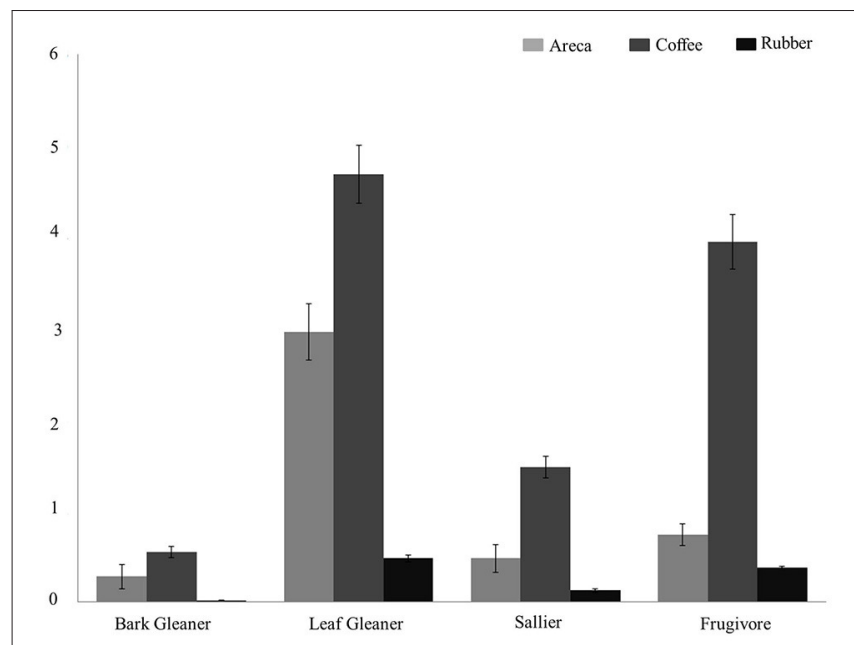

FIGURE 2 | Bird density (per hectare) across the three agroforests for four feeding guilds: Leaf Gleaners, Frugivores, Salliers, Bark Gleaners. had the highest bird density of 1.29 /ha compared to coffee and rubber.

\section{Factors Associated with Bird Richness}

We found that factors influencing bird species richness varied across the three agroforests. As the top model did not adequately explain the richness estimates in areca, we examined the top five models with a cumulative AICc weight $>$ 0.95 . The standardized $\beta$-coefficients for individual covariates from these five models indicated that percentage tree cover (ptc) was positively associated with bird species richness [example: $\beta$ (SE) for ptc in the top model was $0.12(0.02)$, Table 2]. Tree species richness (trich) also had a positive influence but with smaller effect $[\beta$ (SE) for trich in the top model was $0.04(0.02)$, Table 2]. Other variables in the top models included rainfall, distance to protected area and tree density; however, their effects were smaller (Table 2, Figure 4A).

In coffee, the top ranked model (AICc weight $=0.92)$ included tree species richness, tree density, elevation and distance to protected area (Table 2). Confirming our predictions, elevation seemed to be negatively associated with bird species richness $[\beta(S E)=-0.13(0.02)]$, while tree density within each agroforest had a positive influence $[\beta(S E)=0.14(0.02)]$. Distance to protected area and tree richness had a negative association with the species richness, but with very small beta values (Table 2, Figure 4B). In rubber, rainfall showed positive association with species richness $[\mathrm{Ex}: \beta(S E)=0.19(0.03)$ in the top model]. Distance to protected area, percentage tree cover, tree density and tree species richness did not have substantial influence on avian richness in rubber (Table 2, Figure 4C).

The model deviance for the global model in each candidate set, as a proportion of residual deviance ranged from 0.10 to 0.50 (areca: 0.10; coffee: 0.15 ; rubber: 0.50 ). While this is not a

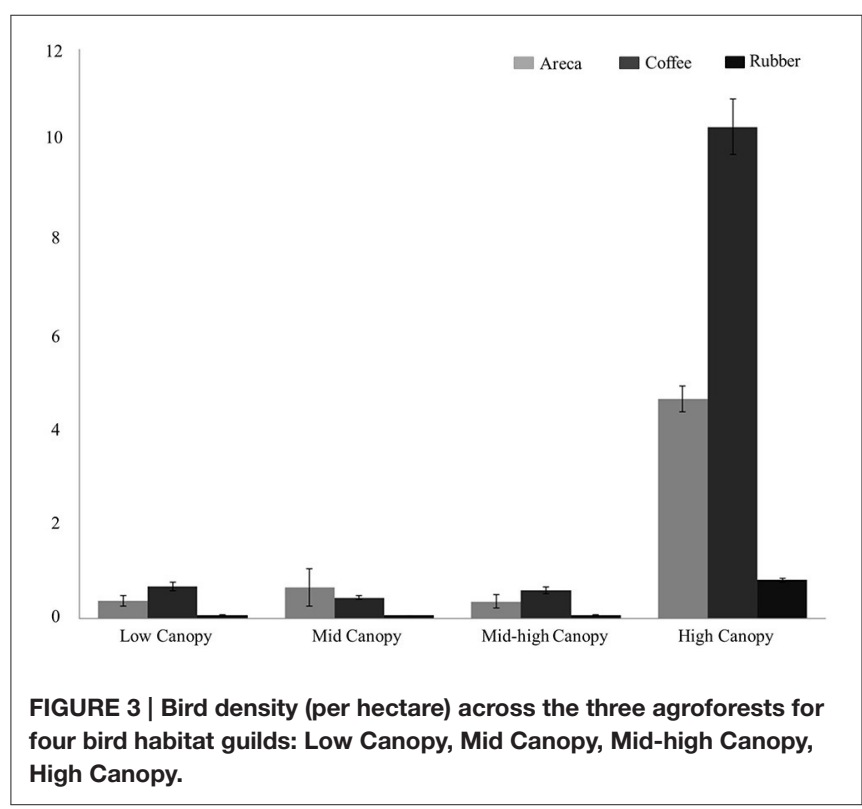


TABLE 2 | Influence of predictors on species richness (Beta co-efficients of top models and associated standard errors).

\begin{tabular}{|c|c|c|c|c|c|c|c|c|c|c|}
\hline Agroforest & Model & Intercept & ${ }^{*}$ ptc & *trich & ${ }^{*}$ tden & *rain & *elv & *dpa & AICc & $\Delta \mathrm{AlCc}$ \\
\hline${ }^{*}$ Range & & & 0-99.99 & $1-31$ & $0-0.17$ & $520-4820$ & $9-1342$ & 0-39.76 & & \\
\hline \multirow[t]{5}{*}{ Areca } & ptc+trich & $2.82(0.02)$ & $0.12(0.02)$ & $0.04(0.02)$ & - & - & - & - & 699.47 & 0 \\
\hline & ptc+trich+rain & $2.82(0.02)$ & $0.17(0.04)$ & $0.04(0.02)$ & - & $-0.06(0.04)$ & - & - & 699.58 & 0.11 \\
\hline & ptc+trich+dpa & $2.82(0.02)$ & $0.12(0.02)$ & $0.04(0.02)$ & - & - & - & $-0.03(0.02)$ & 699.84 & 0.37 \\
\hline & ptc+trich+tden & $2.82(0.02)$ & $0.12(0.02)$ & $0.04(0.02)$ & $-0.004(0.02)$ & - & - & - & 701.70 & 2.24 \\
\hline & ptc+trich+tden+rain+dpa & $2.82(0.02)$ & $0.17(0.04)$ & $0.05(0.02)$ & $-0.02(0.02)$ & $-0.07(0.04)$ & - & $-0.03(0.02)$ & 701.81 & 2.34 \\
\hline Coffee & trich+tden+elev+dpa & $2.58(0.02)$ & - & $-0.06(0.02)$ & $0.14(0.02)$ & & $-0.13(0.02)$ & $-0.01(0.01)$ & 899.38 & 0 \\
\hline \multirow[t]{5}{*}{ Rubber } & ptc+tden+rain+dpa & $2.96(0.02)$ & $-0.06(0.02)$ & - & $0.02(0.02)$ & $0.19(0.03)$ & - & $0.05(0.03)$ & 715.72 & 0 \\
\hline & ptc+tden+rain & $2.96(0.02)$ & $-0.05(0.02)$ & - & $0.03(0.02)$ & $0.15(0.02)$ & - & - & 715.77 & 0.05 \\
\hline & ptc+trich+tden+rain+dpa & $2.96(0.02)$ & $-0.06(0.02)$ & $0.01(0.02)$ & $0.02(0.02)$ & $0.2(0.03)$ & - & $0.05(0.03)$ & 717.68 & 1.97 \\
\hline & tden+rain & $2.96(0.02)$ & - & - & $0.02(0.02)$ & $0.14(0.02)$ & - & - & 718.73 & 3.02 \\
\hline & tden+rain+dpa & $2.96(0.02)$ & - & - & $0.01(0.02)$ & $0.16(0.03)$ & - & $0.02(0.03)$ & 720.33 & 4.61 \\
\hline
\end{tabular}

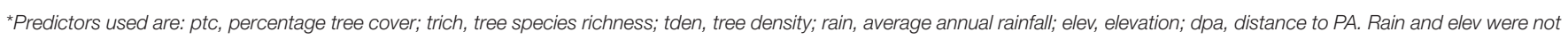
used together in any model as they show strong negative correlation; Range, range of values of that predictor.

high value, it may still indicate substantial influence of predictors when considering ecological datasets.

\section{DISCUSSION}

We examined patterns and predictors of bird species richness, guild density and abundance in agroforests of areca, coffee and rubber in India's Western Ghats. Our results focus on coarser patterns (guild-level densities rather than individual densities, richness of all bird species rather than endemics/habitat specialists, etc.). Nonetheless, our results, including estimates of richness, densities, and the ecological drivers of these patterns, are unique in terms of the spatial scale and rigor for this landscape and elsewhere in the tropics.

Within coffee agroforests, arabica and canephora variants are grown under very different shade conditions, with the latter requiring lower shade cover (DaMatta, 2004). Interestingly, we found no significant differences in bird species richness between these coffee variants. However, contrary to our expectations, rubber agroforests (with little or no understory) showed higher bird species richness than areca. This unexpected result may also be an artifact of spatial autocorrelation of data points within areca agroforests. We found 13 endemics across these agroforests that belonged to the high canopy and are habitat generalists. The 13 other endemics that were not documented in our surveys are low canopy dwellers. It is likely that the poor understory vegetation structure in all three agroforest types constrains the distributions of such endemics in this landscape. This corroborates de Lima et al. (2013) who found that canopy cover was the best predictor of the shift between endemic and non-endemic species, and allowed identifying differences in the local responses of bird assemblages to crop type and land-use change.

Coffee agroforests supported higher bird densities in all four feeding guilds. Particularly among the frugivores and salliers, mean estimated density was much lower in areca and rubber compared to coffee. Populations of sensitive, large-bodied frugivorous species such as hornbills and pigeons are most affected by areca and rubber agroforests. This in turn destabilizes crucial mutualistic plant-frugivore networks and ecosystem functioning (Vidal et al., 2014). Coffee agroforests also supported highest densities of low, mid-high and high canopy habitat guilds. Only for the mid-canopy habitat guild, areca agroforests have higher densities of birds. Although rubber agroforests supported higher bird diversity than areca, rubber consistently had the lowest densities across all guilds. Arriaga-Weiss et al. (2008) in Mexico found that larger fragments supported higher richness and abundance, and influenced composition of habitat guilds as well. In our case, coffee clearly supported a greater diversity of guilds compared to areca and rubber. Therefore, conversions of land between these three agroforests can significantly alter the bird communities found in the landscape. Currently, there is some evidence that areca growers in the region are switching to rubber, and we expect that, at a landscape scale, this will have significant impacts on bird communities (Robbins et al., 2015), as has occurred in Guatemala (Haggar et al., 2013) and Costa Rica (Karp et al., 2012).

Lastly, we examined factors influencing species richness across agroforests. As predicted, percentage tree cover and tree species richness were clearly associated with higher bird species richness in areca, and less clearly in coffee and rubber agroforests (Table 2). Similarly, tree density was unambiguously associated with higher species richness in coffee, and to a lower extent in areca and rubber. Overall, percentage tree cover had a substantial positive influence on bird species richness particularly in areca agroforests. Anand et al. (2010) in their meta-analysis of 35 studies examining 14 taxonomic groups found that forest cover was a major influence on vertebrates in human-modified landscapes of the Ghats. Clough et al. (2009) found that higher bird species richness in Indonesian cacao plantations was associated with tree density and Janowski et al. (2012) found that tree species composition to influence bird species richness in the Andes. Bhagwat et al. (2005) have demonstrated that tree cover may reduce the influence of patch 

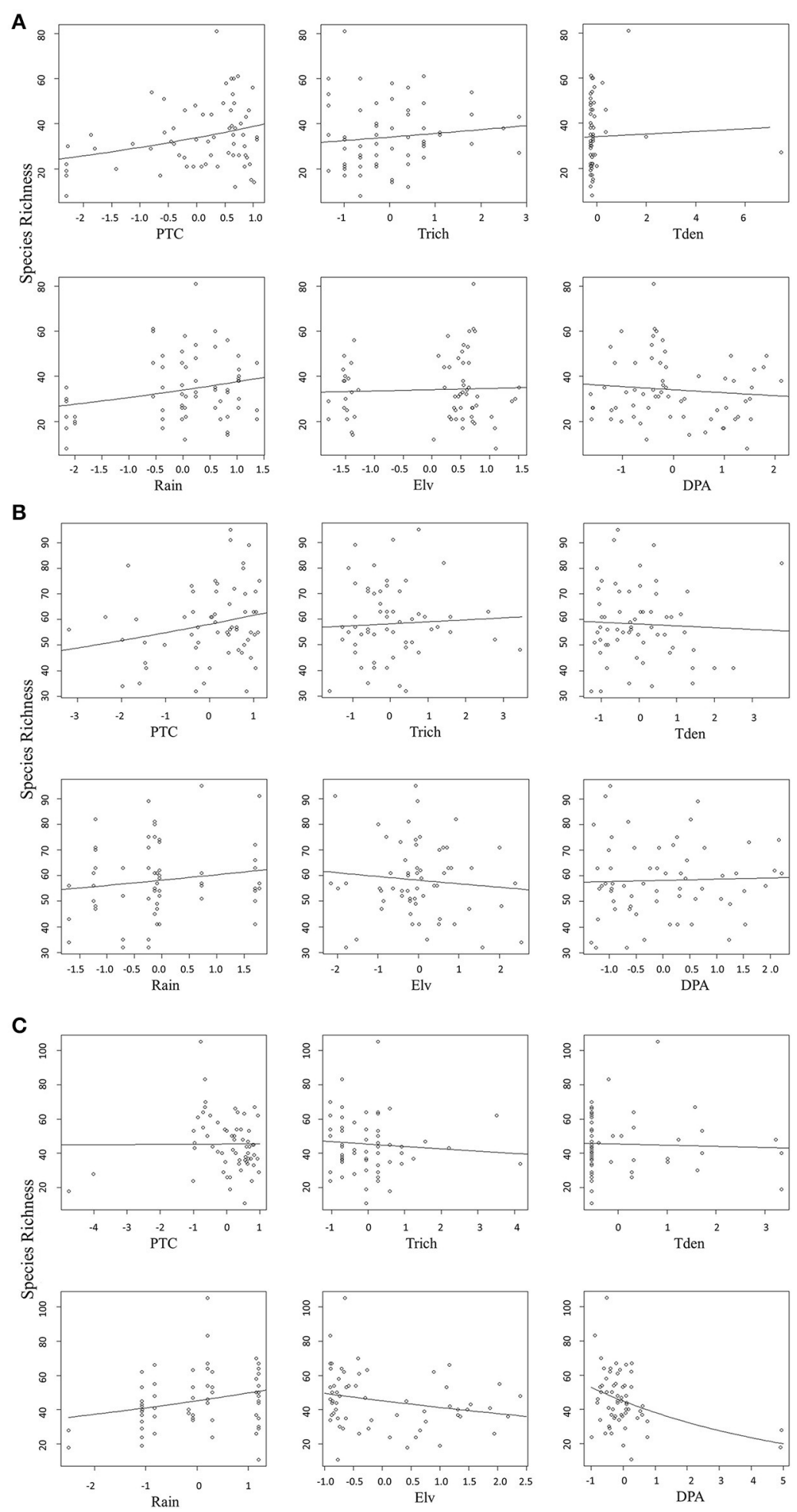

FIGURE 4 | (A) Relationship between predictors and bird species richness in areca agroforests. (B) Relationship between predictors and bird species richness in coffee agroforests. (C) Relationship between each predictor and bird species richness in rubber agroforests. 
area or isolation on species richness and have a buffering impact on biodiversity loss within human-cultivated landscapes in the Western Ghats.

We found some positive associations of rainfall with richness in rubber, and contrary to our expectations, negative associations in areca. With regard to elevation, we found significant support for a negative association in coffee but not in areca or rubber agroforests. Since coffee agroforests in our study ranged from mid to high elevations, our data is consistent with the frequently observed mid-domain effect in bird species richness (Wu et al., 2013). Lastly, bird species richness decreased with increasing distance from protected areas in some of the top ranked models in areca and coffee, but not in rubber. However, we note that the three agroforests are naturally grown at different elevations and geographical locations within Karnataka. This collinearity between agroforest type and various environmental predictors makes it difficult to delineate and interpret the influence of habitat and biogeographic predictors from bird richness patterns (Karp et al., 2012) in an observational study such as ours. Furthermore, in our analyses we find that the areca agroforest plantations are not spatially independent. While we can confidently interpret the results from coffee and rubber agroforests, our inferences of birds in areca are necessarily restricted.

Most previous studies in the tropics have reported higher bird species richness in forested areas than in nearby agroecosystems (Thiollay, 1995; Daily et al., 2001; Naidoo, 2004; see Gove et al., 2008). Our study focused on understanding differences in bird communities between different agroforest types. We did not directly survey protected reserves in this landscape. However, we extracted bird checklists documented from protected reserves in close proximity to our sites that were available on the open-source eBird website (eBird, 2012). We compared these to our results (Supplementary Table 2). We observed that overall species richness for protected reserves were higher than for cultivated agroforests (but these checklists also included wetland and grassland species found within protected areas). Importantly, overall species pool reported ranged between 151 and 253 birds across these protected reserves (Bhadra 248, Durga 151, Nagarahole 273, Dandeli 253, Anshi 218; Supplementary Table 2). With coffee in particular, we speculate that the higher species richness is partly due to better habitat characteristics such as more native shade trees which is similar to habitats within protected reserves. We do not include the eBird data in our analysis, as these are natural history observations where it would be difficult to account for observation errors such as imperfect detectability, unequal sampling effort and species misidentifications.

Our assessments differ from previous studies in some key aspects. We deduced a priori predictions about variations in bird species richness and guild composition across three agroforests, and collected primary data applying a systematic and robust sampling framework (Newbold et al., 2013). We sampled 187 agroforests covering 29,634 $\mathrm{km}^{2}$ area, making it one of the largest field-based assessments of bird species outside protected areas in the Asian tropics (Gardner et al.,
2009; Beaudrot et al., 2016). Our sampling extends the findings of Bali et al. (2007) and Anand et al. (2008), by allowing comparisons across multiple agroforests (DeFries et al., 2010; Beaudrot et al., 2016). Finally, by accounting for detectability we avoided biases in inferred habitat relationships that are likely when both detectability and the state variables of interest (species density, richness) co-vary with habitat variables (Nichols et al., 1998).

We submit that our study provides important yet preliminary insights into factors that influence bird diversity in humandominated agroforests. This sets the background for further analyses of bird-habitat relationships at multiple spatial scales, particularly of species that are of ecological and conservation importance. Opportunities for future research include comparisons of multiple land uses with protected reserves, as well as examining spatial dynamics (such as local extinction, colonization, turnover and change in occupancy) over time (Janowski et al., 2012; Irizarry et al., 2016). This requires establishing long-term monitoring studies of bird communities in the region.

Our results suggest that these production landscapes with privately owned agroforests play a supplementary role (along with protected areas which cover $<9 \%$ of the Western Ghats) in conserving avian diversity. These results have direct consequences for current land-sharing management practices including land conversions (change in crop type), pesticide use, maintaining understory and native tree cover. Given the sensitivity of coffee, rubber and areca cropping strategies, particularly with shifting farm gate prices, current subsidy packages, costs of inputs and labor, as well as larger cultural and political conditions (Hausermann, 2014; Robbins et al., 2015; Warren-Thomas et al., 2015), the conservation of biodiversity in the Ghats requires linking of land-sharing and land-sparing approaches (Das et al., 2006; Karp et al., 2012; Haggar et al., 2013). Policy shifts and role of global-local markets for these commodities will need to further "value" these landscapes to ensure effective biodiversity conservation outcomes.

\section{AUTHOR CONTRIBUTIONS}

$\mathrm{KK}, \mathrm{VS}, \mathrm{SD}, \mathrm{AS}, \mathrm{PR}$, and $\mathrm{AC}$ conceived and designed the experiments. VS and SD performed the experiments. VS, AS, RP, and SS analyzed the data. KK, VS, SD, AS, RP, PR, and AC wrote the manuscript.

\section{ACKNOWLEDGMENTS}

We acknowledge support from Wildlife Conservation Society, Centre for Wildlife Studies, University of Wisconsin-Madison, University of Illinois-UC and Indian School of Business for institutional support. We thank K. U. Karanth, N. Samba Kumar, J. D. Nichols, M. C. Vinay Kumar, M. Amarnath, D. Jathanna, J. Krishnaswamy, N. Page, R. Singal, B. Manjunath, R. Jhambekar, J. Seshadri, D. Jois, T. Gopalaswamy, B. Ramesh, K. Hirdode, S. Nambiar, A. Mendis, P. Modi, S. Prabhu, A. Jamalabad, M. K. 
Rashmi, P. Prasad, A. Surendra, and A. Srimathi for support. We thank all the volunteers: A. Dey, A. Jain, K. Keerthi, S. Sawant, A. Belliappa, C. Bandi, A. Munje, V. Chourasiya, A. Ashratha, V. Jathar, H. P. Hari, S. Nayak, and V. Gupta who assisted with fieldwork. We are grateful to B. M. Akarsha, D. V. Girish, S. Hulikere, H. B. Rajgopal, H. B. Arjun, M. Nanjappa, and A. Goel whose advice and help was invaluable to carrying out the fieldwork. We acknowledge the 187 plantation owners who

\section{REFERENCES}

Ali, S., and Ripley, S. D. (1983). Compact Handbook of the Birds of India and Pakistan: Together with Those of Bangladesh, Nepal, Bhutan, and Sri Lanka. Delhi: Oxford University Press.

Anand, M. O., Krishnaswamy, J., and Das, A. (2008). Proximity to forests drives bird conservation values of coffee plantations: implications for certification. Ecol. Appl. 18, 1754-1763. doi: 10.1890/07-1545.1

Anand, M. O., Krishnaswamy, J., Kumar, A., and Bali, A. (2010). Sustaining biodiversity conservation in human-modified landscapes in the Western Ghats: remnant forests matter. Biol. Conserv. 143, 2363-2374. doi: 10.1016/j.biocon.2010.01.013

Arriaga-Weiss, S. L., Calmé, S., and Kampichler, C. (2008). Bird communities in rainforest fragments: guild responses to habitat variables in Tabasco, Mexico. Biodivers. Conserv. 17, 173-190. doi: 10.1007/s10531-007-9238-7

Bali, A., Kumar, A., and Krishnaswamy, J. (2007). The mammalian communities in coffee plantations around a protected area in the Western Ghats, India. Biol. Conserv. 139, 93-102. doi: 10.1016/j.biocon.2007.06.017

Balmford, A., Green, R. E., and Scharlemann, J. P. W. (2005). Sparing land for nature: exploring the potential impact of changes in agricultural yield on the area needed for crop production. Glob. Chang. Biol. 11, 1594-1605. doi: 10.1111/j.1365-2486.2005.001035.x

Beaudrot, L., Ahumada, J. A., O’Brien, T., Alvarez-Loayza, P., Boekee, K., CamposArceiz, A., et al. (2016). Standardized assessment of biodiversity trends in tropical forest protected areas: the end is not in sight. PLoS Biol. 14:e1002357. doi: 10.1371/journal.pbio.1002357

Bhagwat, S. A., Kushalappa, C. G., Williams, P. H., and Brown, N. D. (2005). A landscape approach to biodiversity conservation of sacred groves in the Western Ghats of India. Conserv. Biol. 19, 1853-1862. doi: 10.1111/j.15231739.2005.00248.x

Bhagwat, S. A., Willis, K. J., Birks, H. J. B., and Whittaker, R. J. (2008). Agroforestry: a refuge for tropical biodiversity? Trends Ecol. Evol. 23, 261-267. doi: 10.1016/ j.tree.2008.01.005

Buckland, S. T., Anderson, D. R., Burnham, K. P., Laake, J. L., Borchers, D. L., and Thomas, L. (2001). Introduction to Distance Sampling. Oxford: Oxford University Press.

Burnham, K. P., and Anderson, D. R. (2002). Model Selection and Multimodel Inference: A Practical Information-Theoretic Approach. New York, NY: Springer Science \& Business Media.

Cam, E., Nichols, J. D., Sauer, J. S., and Hines, J. E. (2002). On the estimation of species richness based on the accumulation of previously unrecorded species. Ecography 25, 102-108. doi: 10.1034/j.1600-0587.2002.250112.x

Clough, Y., Dwi Putra, D., Pitopang, R., and Tscharntke, T. (2009). Local and landscape factors determine functional bird diversity in Indonesian cacao agroforestry. Biol. Conserv. 142, 1032-1041. doi: 10.1016/j.biocon.2008. 12.027

Coffee Board of India (2013). Official Website of the Coffee Board of India. Available online at: http://www.indiacoffee.org (Accessed January 2013).

Daily, G. C., Ehrlich, P. R., and Sanchez-Azofeifa, G. A. (2001). Countryside biogeography: use of human-dominated habitats by the avifauna of southern Costa Rica. Ecol. Appl. 11, 1-13. doi: 10.1890/1051-0761 (2001)011[0001:CBUOHD]2.0.CO;2

DaMatta, F. M. (2004). Ecophysiological constraints on the production of shaded and unshaded coffee: a review. Field Crops Res. 86, 99-114. doi: 10.1016/j.fcr. 2003.09.001 allowed us to conduct the sampling. This article is based upon research supported by NSF Grant Number 1265223.

\section{SUPPLEMENTARY MATERIAL}

The Supplementary Material for this article can be found online at: http://journal.frontiersin.org/article/10.3389/fevo. 2016.00111
Das, A., Krishnaswamy, J., Bawa, K. S., Kiran, M. C., Srinivas, V., Kumar, N. S., et al. (2006). Prioritisation of conservation areas in the Western Ghats, India. Biol. Conserv. 133, 16-31. doi: 10.1016/j.biocon.2006.05.023

DeFries, R., Karanth, K. K., and Pareeth, S. (2010). Interactions between protected areas and their surroundings in human-dominated tropical landscapes. Biol. Conserv. 143, 2870-2880. doi: 10.1016/j.biocon.2010.02.010

de Lima, R. F., Dallimer, M., Atkinson, P. W., and Barlow, J. (2013). Biodiversity and land-use change: understanding the complex responses of an endemic-rich bird assemblage. Divers. Distrib. 19, 411-422. doi: 10.1111/ddi.12015

eBird (2012). eBird: An Online Database of Bird Distribution and Abundance [Web Application]. Ithaca, NY: eBird. Available online at: http://www.ebird.org

Faria, D., Laps, R. R., Baumgarten, J., and Cetra, M. (2006). Bat and bird assemblages from forests and shade cacao plantations in two contrasting landscapes in the Atlantic Forest of southern Bahia, Brazil. Biodivers. Conserv. 15, 587-612. doi: 10.1007/s10531-005-2089-1

Fischer, J., Brosi, B., Daily, G. C., Ehrlich, P. R., Goldman, R., Goldsten, J., et al. (2008). Should agricultural policies encourage land sparing or wildlife-friendly farming? Front. Ecol. Environ. 6, 380-385. doi: 10.1890/070019

Foley, J. A., Ramankutty, N., Brauman, K. A., Cassidy, E. S., Gerber, J. S., Johnston, M., et al. (2011). Solutions for a cultivated planet. Nature 478, 337-342. doi: 10.1038 /nature 10452

Garcia, C. A., Bhagwat, S. A., Ghazoul, J., Nath, C. D., Nanaya, K. M., Kushalappa, C. G., et al. (2010). Biodiversity conservation in agricultural landscapes: challenges and opportunities of coffee agroforests in the Western Ghats, India. Conserv. Biol. 24, 479-488. doi: 10.1111/j.1523-1739.2009.01386.x

Gardner, T. A., Barlow, J., Chazdon, R., Ewers, R., Harvey, C. A., Peres, C. A., et al. (2009). Prospects for tropical forest biodiversity in a human-modified world. Ecol. Lett. 12, 561-582. doi: 10.1111/j.1461-0248.2009.01294.x

Gove, A. D., Hylander, K., Nemomisa, S., and Shimelis, A. (2008). Ethiopian coffee cultivation-Implications for bird conservation and environmental certification. Conserv. Lett. 1, 208-216. doi: 10.1111/j.1755-263X.2008.00033.x

Grimmett, R., Inskipp, T., and Inskipp, C. (1998). Birds of the Indian Subcontinent. New Delhi: Oxford University Press.

Haggar, J., Medina, B., Aguilar, R. M., and Munoz, C. (2013). Land use change on coffee farms in southern Guatemala and its environmental consequences. Environ. Manage. 51, 811-823. doi: 10.1007/s00267-013-0019-7

Hausermann, H. (2014). Maintaining the coffee canopy: understanding change and continuity in central Veracruz. Hum. Ecol. 42, 381-394. doi: 10.1007/s10745014-9644-x

Irizarry, J. I., Collazo, J. A., and Dinsmore, S. J. (2016). Occupancy dynamics in human-modified landscapes in a tropical island: implications for conservation design. Diver. Distrib. 22, 410-421. doi: 10.1111/ddi.12415

Janowski, J. E., Merkord, C. L., Rios, W. F., Cabrera, K. G., Revilla, N. S., and Silman, M. R. (2012). The relationship of tropical bird communities to tree species composition and vegetation structure along an Andean elevational gradient. J. Biogeog. 40, 950-962. doi: 10.1111/jbi.12041

Karp, D. S., Rominger, A. J., Zook, J., Ranganathan, J., Ehrlich, P. R., and Daily, G. C. (2012). Intensive agriculture erodes $\beta$-diversity at large scales. Ecol. Lett. 15, 963-970. doi: 10.1111/j.1461-0248.2012.01815.x

Larsen, F. W., Bladt, J., Balmford, A., and Rahbek, C. (2012). Birds as biodiversity surrogates: will supplementing birds with other taxa improve effectiveness? J. Appl. Ecol. 49, 349-356. doi: 10.1111/j.1365-2664.2011.02094.x

Maas, B., Clough, Y., and Tscharntke, T. (2013). Bats and birds increase crop yield in tropical agroforestry landscapes. Ecol. Lett. 16, 1480-1487. doi: 10.1111/ele. 12194 
Maas, B., Dwi Putra, D., Waltert, M., Clough, Y., Tscharntke, T., and Schulze, C. H. (2009). Six years of habitat modification in a tropical rainforest margin of Indonesia do not affect bird diversity but endemic forest species. Biol. Conserv. 142, 2665-2671. doi: 10.1016/j.biocon.2009. 06.018

Melles, S., Glenn, S., and Martin, K. (2003). Urban bird diversity and landscape complexity: species-environment associations along a multiscale habitat gradient. Ecol. Soc. 7:5. Available online at: http://hdl.handle.net/10535/3247

Mendenhall, C. D., Frishkoff, L. O., Santos-Barrera, G., Pacheco, J., Mesfun, E., Quijano, F. M., et al. (2014). Countryside biogeography of Neotropical reptiles and amphibians. Ecology 95, 856-870. doi: 10.1890/12-2017.1

Menon, S., and Bawa, K. S. (1997). Applications of geographic information systems, remote-sensing, and a landscape ecology approach to biodiversity conservation in the Western Ghats. Curr. Sci. 73, 134-145.

Ministry of Agriculture (2013). Official Website of the Department of Agriculture, Cooperation and Farmers Welfare. Available online at: http://agricoop.nic.in/ (Accessed January 2013).

Mitchell, K. (2007). Quantitative Analysis by the Point-Centered Quarter Method. Geneva, NY: Hobart and William Smith Colleges.

Mulwa, R. K., Bohning-Gaese, K., and Schleuning, M. (2012). High bird species diversity in structurally heterogeneous farmland in Western Kenya. Biotropica 44, 801-809. doi: 10.1111/j.1744-7429.2012.00877.x

Naidoo, R. (2004). Species richness and community composition of songbirds in a tropical forest-agricultural landscape. Anim. Conserv. 7, 93-105. doi: $10.1017 /$ S1367943003001185

Newbold, T., Scharlemann, J. P. W., Butchart, S. H. M., Şekercioğlu, Ç. H., Alkemade, R., Booth, H., et al. (2013). Ecological traits affect the response of tropical forest bird species to land-use intensity. Proc. R. Soc. B 280:20122131. doi: $10.1098 /$ rspb.2012.2131

Nichols, J. D., Bailey, L. L., O’Connell, A. F. Jr., Talancy, N. W., Grant, E. H. C., Gilbert, A. T., et al. (2008). Multi-scale occupancy estimation and modelling using multiple detection methods. J. Appl. Ecol. 45, 1321-1329. doi: 10.1111/j.1365-2664.2008.01509.x

Nichols, J. D., Boulinier, T., Hines, J. E., Pollock, K. H., and Sauer, J. R. (1998). Inference methods for spatial variation in species richness and community composition when not all species are detected. Conserv. Biol. 6, 1390-1398. doi: 10.1111/j.1523-1739.1998.97331.x

Perfecto, I., and Vandermeer, J. (2008). Biodiversity conservation in tropical agroecosystems - a new conservation paradigm. Ann. N. Y. Acad. Sci. 1134, 173-200. doi: 10.1196/annals.1439.011

Petit, L., and Petit, D. (2003). Evaluating the importance of human-modified lands for neotropical bird conservation. Conserv. Biol. 17, 687-694. doi: 10.1046/j.1523-1739.2003.00124.x

Pryde, E. C., Nimmo, D. G., Holland, G. J., and Watson, S. J. (2016). Species' traits affect the occurrence of birds in a native timber plantation landscape. Anim. Conserv. doi: 10.1111/acv.12268. [Epub ahead of print].

Ramsey, F., and Schafer, D. (2012). The Statistical Sleuth: A Course in Methods of Data Analysis. Boston, MA: Cengage Learning.

Ranganathan, J., Daniels, R. J. R., Chandran, M. D. S., Ehrlich, P. R., and Daily, G. C. (2008). Sustaining biodiversity in ancient tropical countryside. Proc. Natl. Acad. Sci. U.S.A. 105, 17852-17854. doi: 10.1073/pnas.0808 874105
Ranganathan, J., Krishnaswamy, J., and Anand, M. O. (2010). Landscapelevel effects on avifauna within tropical agriculture in the Western Ghats: insights for management and conservation. Biol. Cons. 143, 2909-2917. doi: 10.1016/j.biocon.2010.04.018

R Development Core Team (2014). RStudio: Integrated Development for R. RStudio, Inc. Boston, MA: R Development Core Team.

Rexstad, E., and Burnham, K. P. (1991). User's Guide for Interactive Program CAPTURE. Reston, VA: Cooperative Fish and Wildlife Research Unit.

Robbins, P., Chaatre, A., and Karanth, K. (2015). Political ecology of commodity agroforests and tropical biodiversity. Conserv. Lett. 8, 77-85. doi: $10.1111 /$ conl.12169

Rubber Board of India (2013). Official Website of the Rubber Board of India. Available online at: http://rubberboard.org.in/ (Accessed January 2013).

Ruiz-Gutierrez, V., Elise, F., Zipkin, E. F., and Dhondt, A. A. (2010). Occupancy dynamics in a tropical bird community: unexpectedly high forest use by birds classified as non-forest species. J. Appl. Ecol. 47, 621-630. doi: 10.1111/j.13652664.2010.01811.x

Runkle, J. R. (2000). Canopy tree turnover in old-growth mesic forests of eastern North America. Ecology 81, 554-567. doi: 10.1890/0012-9658(2000) 081[0554:CTTIOG]2.0.CO;2

Thiollay, J.-M. (1995). The role of traditional agroforests in the conservation of rain forest bird diversity in sumatra. Conserv. Biol. 9, 335-353. doi: 10.1046/j.15231739.1995.9020335.x

Thomas, L., Laake, J. L., Strindberg, S., Marques, F. F. C., Buckland, S. T., Borchers, D. L., et al. (2006). Distance 6.0. Release 2. Research Unit for Wildlife Population Assessment, University of St. Andrews, UK.

Tscharntke, T., Clough, Y., Wanger, T. C., Jackson, L., Motzke, I., Perfecto, I., et al. (2012). Global food security, biodiversity conservation and the future of agricultural intensification. Biol. Conserv. 151, 53-59. doi: 10.1016/j.biocon. 2012.01.068

Vidal, M. M., Hasui, E., Pizo, M. A., Tamashiro, J. Y., Silva, W. R., and Guimarães, P. R. Jr. (2014). Frugivores at higher risk of extinction are the key elements of a mutualistic network. Ecology 95, 3440-3447. doi: 10.1890/13-1584.1

Warren-Thomas, E., Dolman, P. M., and Edwards, D. P. (2015). Increasing demand for natural rubber necessitates a robust sustainability initiative to mitigate impacts on tropical biodiversity. Conserv. Lett. 8, 230-241. doi: $10.1111 /$ conl.12170

Wu, Y., Colwell, R. K., Rahbek, C., Zhang, C., Quan, Q., Wang, C., et al. (2013). Explaining the species richness of birds along a subtropical elevational gradient in the Hengduan Mountains. J. Biogeogr. 40, 2310-2323. doi: 10.1111/jbi.12177

Conflict of Interest Statement: The authors declare that the research was conducted in the absence of any commercial or financial relationships that could be construed as a potential conflict of interest.

Copyright (c) 2016 Karanth, Sankararaman, Dalvi, Srivathsa, Parameshwaran, Sharma, Robbins and Chhatre. This is an open-access article distributed under the terms of the Creative Commons Attribution License (CC BY). The use, distribution or reproduction in other forums is permitted, provided the original author(s) or licensor are credited and that the original publication in this journal is cited, in accordance with accepted academic practice. No use, distribution or reproduction is permitted which does not comply with these terms. 